\title{
Fractal analysis of dendritic arborization patterns of pyramidal neurons in human basolateral amygdala Jovo Tosevski*1, Predrag Sazdanovic ${ }^{1}$, Ivana Zivanovic-Macuzicㄹ, Maja Stankovic Vulovic ${ }^{1}$, Dejan Jeremic ${ }^{1}$, Nebojsa Milosevic ${ }^{2}$ and Dusan Ristanovic ${ }^{2}$
}

\author{
Address: ${ }^{1}$ Institute of Anatomy, School of Medicine, University of Kragujevac, Serbia and ${ }^{2}$ Institute of Biophysics, School of Medicine, University \\ of Belgrade, Serbia \\ * Corresponding author
}

\author{
from International Society on Brain and Behaviour: 3rd International Congress on Brain and Behaviour \\ Thessaloniki, Greece. 28 November - 2 December 2007 \\ Published: 17 April 2008 \\ Annals of General Psychiatry 2008, 7(Suppl I):SI4I doi:I0.II86/I744-859X-7-SI-SI4I
}

This abstract is available from: http://www.annals-general-psychiatry.com/content/7/SI/SI4I

(c) 2008 Tosevski et al.; licensee BioMed Central Ltd.

\section{Background}

It is well known that there is important role of amygdala in emotional-cognitive processes, i.e. in emotional and associative learning, fear acquisition and emotional memory [1]. We investigated dendritic branching patterns of pyramidal neurons which are believed to be excitatory. According to our earlier findings pyramidal neurons in human basolateral amygdala have two subtypes - pyramidal slender and pyramidal squat neurons [2]. Fractal analysis, which comes from Mandelbrot's fractal geometry [3], is used as a tool for differentiation of the complexity of neuronal dendritic branching patterns. The measure of dendritic branching represents the fractal dimension of the neuron. In performing this study, we have applied the fractal analysis to the images of neurons, in order to investigate its capability to distinguish between subtypes.

\section{Materials and methods}

The images of 14 Golgi-impregnated neurons were classified into two categories based on their somata and dendritic patterns - pyramidal slender and pyramidal squat subtypes. All images were analyzed with the box-counting method using public domain Image J software [4].

\section{Results}

Statistical analysis of the obtained data indicated that there was a significant difference $(\mathrm{p}<0.05)$ between the calculated means of fractal dimensions between dendritic arbors of two subtypes - slender and squat pyramidal neurons.

\section{Conclusions}

This preliminary study of neuronal structure performed on pyramidal neurons of human basolateral amygdala suggests the utility both of fractal analysis and fractal dimension as a useful parameter of the complexity of dendritic structure and indicates their functional complexity.

\section{References}

I. McGaugh JL: The amygdala modulates the consolidation of memories of emotionally arousing experiences. Annu Rev Neurosci 2004, 27:I-28.

2. Tosevski J, Malikovic A, Mojsilovic-Petrovic J, et al: Types of neurons and some dendritic patterns of basolateral amygdala in humans - a Golgi study. Ann Anat 2002, 184:93-103.

3. Mandelbrot BB: The Fractal Geometry of Nature. 20th ed edition. New York: W.N. Freemen and Co; 2004.

4. Milosevic NT, Ristanovic D, Stankovic JB: Fractal analysis of the laminar organization of spinal cord neurons. J. Neurosci. Meth 2005, I 46: 198-204. 